Subscriber access provided by Uppsala universitetsbibliotek

\title{
Article
}

\section{Coumarin-Containing Pillar[5]arenes as Multifunctional Liquid Crystal Macrocycles}

Alberto Concellón, Pilar Romero, Mercedes Marcos, Joaquín Barberá, Carlos SánchezSomolinos, Masayuki Mizobata, Tomoki Ogoshi, José Luis Serrano, and Jesus del Barrio

J. Org. Chem., Just Accepted Manuscript • DOI: 10.1021/acs.joc.0c00852 • Publication Date (Web): 16 Jun 2020

Downloaded from pubs.acs.org on June 17, 2020

\section{Just Accepted}

"Just Accepted" manuscripts have been peer-reviewed and accepted for publication. They are posted online prior to technical editing, formatting for publication and author proofing. The American Chemical Society provides "Just Accepted" as a service to the research community to expedite the dissemination of scientific material as soon as possible after acceptance. "Just Accepted" manuscripts appear in full in PDF format accompanied by an HTML abstract. "Just Accepted" manuscripts have been fully peer reviewed, but should not be considered the official version of record. They are citable by the Digital Object Identifier (DOI®). "Just Accepted" is an optional service offered to authors. Therefore, the "Just Accepted" Web site may not include all articles that will be published in the journal. After a manuscript is technically edited and formatted, it will be removed from the "Just Accepted" Web site and published as an ASAP article. Note that technical editing may introduce minor changes to the manuscript text and/or graphics which could affect content, and all legal disclaimers and ethical guidelines that apply to the journal pertain. ACS cannot be held responsible for errors or consequences arising from the use of information contained in these "Just Accepted" manuscripts. 


\title{
Coumarin-Containing Pillar[5]arenes as Multifunctional Liquid Crys- tal Macrocycles
}

\author{
Alberto Concellón, ${ }^{+, \notin, \S}$ Pilar Romero, ${ }^{\dagger}$ Mercedes Marcos, ${ }^{\dagger}$ Joaquín Barberá, ${ }^{+}$Carlos Sánchez-Somolinos, ${ }^{\Phi, \vartheta}$ Masa- \\ yuki Mizobata," Tomoki Ogoshi,",, José Luis Serrano, ${ }^{+, \neq}$Jesús del Barrio. ${ }^{*,+,+, \S}$ \\ †Departamento de Química Orgánica, Instituto de Ciencia de Materiales de Aragón (ICMA), CSIC-Universidad de Zaragoza, 50009

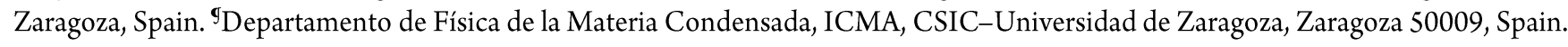 \\ ${ }^{\circ}$ CIBER in Bioengineering, Biomaterials and Nanomedicine (CIBER-BBN) 28029 Madrid, Spain. "Graduate School of Natural Sci- \\ ence and Technology, Kanazawa University, Kakuma-machi, Kanazawa 920-1 192, Japan. "WPI Nano Life Science Institute, Kanazawa \\ University, Kakuma-machi, Kanazawa 920-1192, Japan. ${ }^{\circ}$ Department of Synthetic Chemistry and Biological Chemistry, Graduate \\ School of Engineering, Kyoto University, Katsura, Nishikyo-ku, Kyoto 615-8510, Japan. 'Instituto Universitario de Investigación en \\ Nanociencia de Aragón (INA), Universidad de Zaragoza, 50009 Zaragoza, Spain. Corresponding author Email: jdb529@unizar.es
}

\section{Table of Contents Artwork}

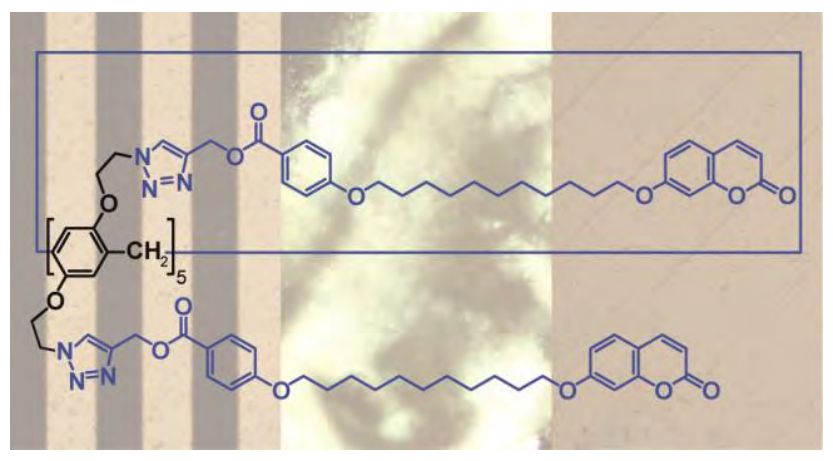

\begin{abstract}
Liquid crystal macrocycles (LCMs) combine the unique properties of liquid crystals with those associated with macrocyclic compounds -shape persistence and the capability of hosting small molecules. Herein we investigate the grafting of coumarin-containing promesogenic moieties to pillar[5] arene as a strategy to obtain multifunctional LCMs. Pillar[5] arenes containing 10 and 30 coumarin units are glassy materials with nematic mesomorphism. Moreover, the coumarin moieties afford the pillar[5]arene derivatives enhanced film-forming and photoresponsive properties. Photodimerization of the coumarin moieties results in cross-linked polymer networks which can be used as alignment layers. Therefore, liquid crystal coumarin-containing pillar[5] arenes represent a significant addition to the family of LCMs and may become useful for the development of engineered, hierarchical structures and materials.
\end{abstract}

\section{INTRODUCTION}

Liquid crystals (LCs) are unique in that they flow yet their constituting molecules exhibit long-range order. ${ }^{1}$ Such a property is at the basis of a plethora of applications, including LCD technology, sensing, optics, soft robotics, as well as electron and ion transporting materials. $^{2-5}$ The engineering of LCs at the molecular level can unlock further opportunities for the development of advanced multifunctional materials. ${ }^{6}$ Specifically, macrocycles are particularly attractive scaffolds for the preparation of multifunctional LCs on account of their shape-persistent cavity and their ability to host small guest molecules. ${ }^{7}$ Liquid crystal macrocycles (LCMs) typically present a central macrocyclic moiety surrounded by promesogenic units, and include, but are not limited to, phenylacetylene and oligopeptide mac rocycles, imidazolium salts, cycloaramides and catenanes. ${ }^{8,9}$ Additionally, they exhibit a specific solid-phase microstructure where each macrocyclic moiety is approximately in register with those below and above it, an ordering which can result in infinite molecular channels embedded in a LC matrix. Thus, LCMs have been proposed as promising candidates for the next-generation materials in nanofiltration and ion-conducting applications. ${ }^{5}$

A more recent addition to the family of LCMs include pil$\operatorname{lar}[n]$ arene derivatives. ${ }^{10}$ Pioneering work on LC pillar[5] arenes by Nierengarten, Deschenaux and co-workers has been followed by an increasing interest in this type of LCMs, where a common approach is based on the functionalization of the rim positions of pil$\operatorname{lar}[n]$ arenes with promesogenic, calamitic or dendritic (Percec-type 
dendrons), moieties. ${ }^{11}$ Pan and co-workers have recently investigated the properties of two pillar[5] arene derivatives containing 10 azobenzene promesogenic moieties. ${ }^{11 \mathrm{c}}$

Inspired by these studies we envisioned that pillar[5]arenes P5-Cou-10 and P5-Cou-30 (Chart 1) would be perfect for the realization of self-organizing materials as they exhibit LC properties and can be cross-linked into polymer networks via coumarin photodimerization. ${ }^{12}$ Herein, we disclose the synthesis of P5-Cou-10 and P5-Cou-30, their LC behavior and host-guest properties. This study lays the ground for our future research on responsive LC materials with shape-persistent cavities and pores of nanoscopic dimensions.

Chart 1. Chemical structures of P5-Cou-10, P5-Cou-30 and 9.

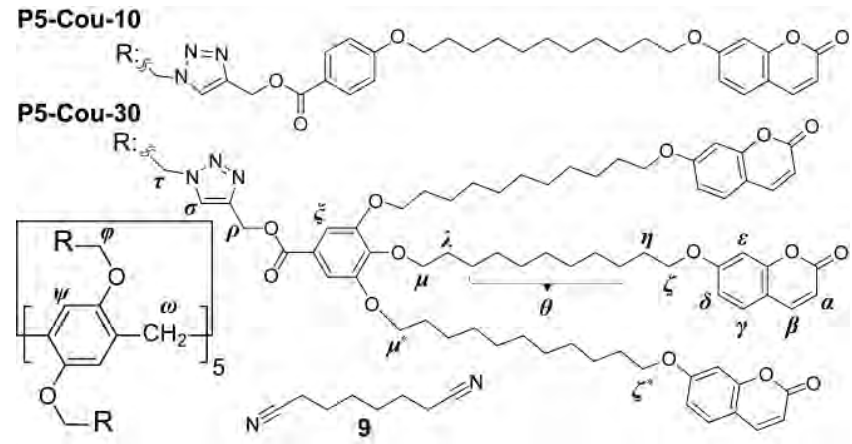

\section{RESULTS AND DISCUSSION}

The synthesis of pillar[5]arene derivatives P5-Cou-10 and P5-Cou-30 relied on the copper-catalyzed alkyne-azide cycloaddition (CuAAC) reaction between decaazide $\mathbf{8}$ and alkyne-functionalized promesogenic moieties 4 and $\mathbf{6}$ (Scheme 1). Compound 4 was synthesized from 7-[(11-bromoundecyl)oxy]-2H-chromen-2one, $\mathbf{1}$, as depicted in Scheme 1a. ${ }^{13}$ In the first step, $\mathbf{1}$ was reacted with methyl 4-hydroxybenzoate under Williamson alkylation conditions to yield 2. Alkaline hydrolysis of the methyl ester group of $\mathbf{2}$ and subsequent esterification with propargyl alcohol resulted in $\mathbf{4}$ (Scheme 1a). Coumarin dendron $\mathbf{6}$ was obtained from $5,{ }^{13}$ after esterification with propargyl alcohol (Scheme $1 \mathrm{~b}$ ). The CuAAC reaction between 8 and alkyne-functionalized coumarin derivatives 4 and 6 was performed in $\mathrm{THF} /$ water at $40^{\circ} \mathrm{C}$ using $\mathrm{CuSO}_{4} \cdot 5 \mathrm{H}_{2} \mathrm{O}$ /sodium ascorbate as catalytic system (Scheme 1c), which has been shown to provide excellent coupling yields. A slight excess of alkynes 4 and 6 was used in each of the CuAAC reactions in order to drive the transformation of the azide groups of $\mathbf{8}$ to completion. The evolution of the CuAAC reaction was monitored by FT-IR spectroscopy. The disappearance of the $-\mathrm{N}_{3}$ stretching vibration signal band at $2089 \mathrm{~cm}^{-1}$ indicated the complete consumption of all the azide groups of $\mathbf{8}$. At this point, an azide-functionalized polystyrene resin was added in order to remove the excess of alkyne. Pillar[5]arenes P5-Cou-10 and P5-Cou-30 were purified by column chromatography and isolated as air-stable gummy solids which are soluble in common solvents such as dichloromethane, chloroform and THF. The ${ }^{1} \mathrm{H}$ NMR and ${ }^{13} \mathrm{C}$ NMR spectra of P5-Cou-10 and P5-Cou-30 are consistent with the proposed chemical structures (Chart 1, Figures $1 \mathrm{a}$ and $\mathrm{S} 9-\mathrm{S} 18$ ). The presence of a signal at ca. $\delta=8.00 \mathrm{ppm}$ in the ${ }^{1} \mathrm{H}$ NMR spectra of P5-Cou-10 and P5-Cou-30 is associated with protons $\mathrm{H} \sigma$ of the final pillar[5] arenes, and evidences the formation of the 1,4-disubstituted 1,2,3-triazole groups in a regiospecific fashion. It is worth noting that protons of the methylene groups $-\mathrm{CH}_{2}-\mathrm{CH}_{2}-\mathrm{N}_{3}$ of $\mathbf{8}$ become diastereotopic in P5-Cou-10 and P5-Cou-30 after the CuAAC reaction and are independently observed (see pairs of signals for $\mathrm{H} \tau$ and $\mathrm{H} \varphi$ in Figure 1a). In addition to ${ }^{1} \mathrm{H}$ NMR analysis, mass spectrometric analysis of P5-Cou-10 and P5-Cou-30 showed the expected $m / z$ peak (Figure S21).

(a)

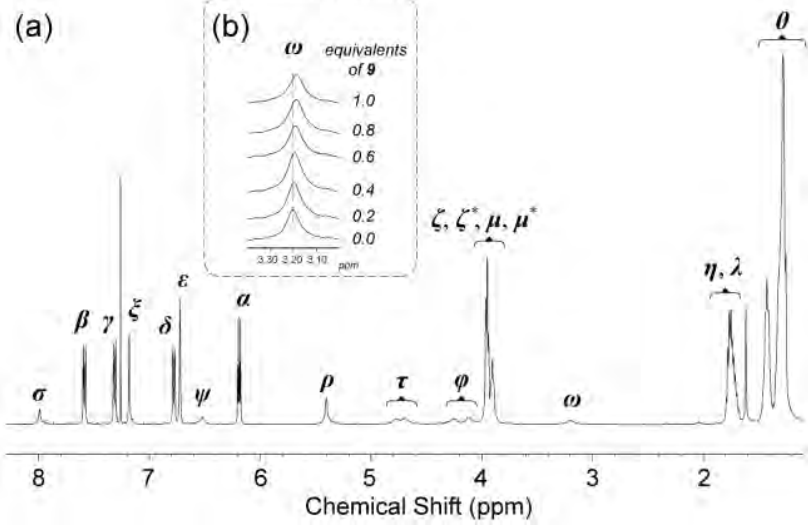

Figure 1. Partial ${ }^{1} \mathrm{H}$ NMR spectrum $\left(500 \mathrm{MHz}, \mathrm{CDCl}_{3}, 298 \mathrm{~K}\right)$ of P5-Cou-30 (a), and selected region of the ${ }^{1} \mathrm{H}$ NMR spectrum of P5-Cou-30 with increasing amounts of 9 (b). For proton labeling, see Chart 1.

The thermal stability of the pillar[5] arenes derivatives was studied by thermogravimetric analysis (TGA), and both P5-Cou-10 and P5-Cou-30 exhibited good thermal stability with $2 \%$ weight loss temperature (T2\%) of T2\% $=256^{\circ} \mathrm{C}$ for P5-Cou-10 and T $2 \%=218$ ${ }^{\circ} \mathrm{C}$ for P5-Cou-30 (Figures S22 and S23), well above the isotropization temperature (vide infra). Thermal transitions and LC properties were studied by polarized optical microscopy (POM) and differential scanning calorimetry (DSC). The most relevant temperature values are gathered in Table 1 .

Table 1. Thermal Stability and Transition Temperatures for P5-Cou-10, P5-Cou-30 and Host-Guest Complexes

\begin{tabular}{ll}
\hline & Phase transitions $^{[\mathrm{a}, \mathrm{b}]}$ \\
\hline P5-Cou-10 & $g 25 N 65-70 I$ \\
P5-Cou-30 & $g 14 N 40-45 I$ \\
9CP5-Cou-10 & $g 1 N 50-55 I^{[\mathrm{c}]}$ \\
9CP5-Cou-30 & $g 2 N 40-45 I$
\end{tabular}

[a] Glass transition temperature, $T_{g}$, determined by DSC (second heating process, rate: $\left.10{ }^{\circ} \mathrm{C} \cdot \mathrm{min}^{-1}\right)$; g: glass, $N$ : nematic mesophase, $I$ : isotropic liquid. [b] $N \rightarrow I$ transition temperature based on POM observations. $[\mathrm{c}] T_{g}$ determined by DSC (first heating process, rate: $\left.10^{\circ} \mathrm{C} \cdot \mathrm{min}^{-1}\right)$; phase separation was observed by POM at $T>55^{\circ} \mathrm{C}$. 

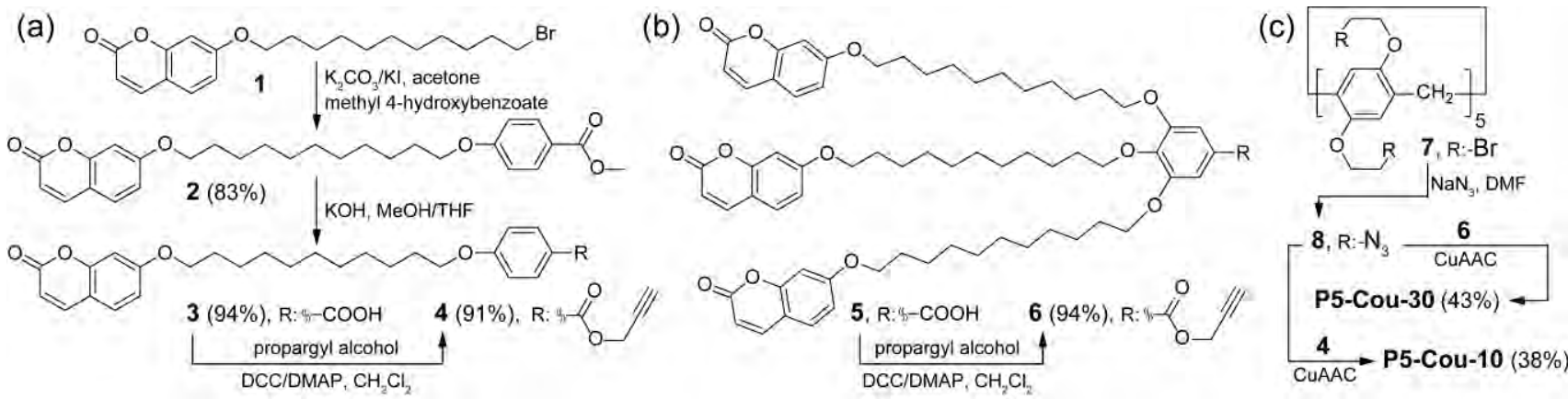

Scheme 1. Synthesis of alkyne-functionalized coumarin derivatives 4 (a) and 6 (b), and pillar[5]arenes P5-Cou-10 and P5-Cou-30 (c).

Parent pillar[5]arene 7 and alkyne 4 are crystalline solids at room temperature (RT), whereas 6 is a semicrystalline compound exhibiting a glass transition at $T_{\mathrm{g}}=-3^{\circ} \mathrm{C}$ and a crystallization process at $T_{\mathrm{c}}=-34^{\circ} \mathrm{C}$ (Figures S24 and S25). Samples of P5-Cou-10 and P5-Cou-30 were heated up to $100{ }^{\circ} \mathrm{C}$ and cooled down to $-40^{\circ} \mathrm{C}$ at $10^{\circ} \mathrm{C} / \mathrm{min}$. Upon heating, only a glass transition was detected which is a signature of their glassy nature (Figure 2a). Under POM, samples of P5-Cou-10 and P5-Cou-30 above $T_{g}$ behaved as highly viscous fluids and exhibited LC properties (Figure $2 \mathrm{~b}$, the observations were performed while applying pressure to the samples on account of their spontaneous homeotropic alignment). Both pillar[5]arene derivatives exhibited enantiotropic mesomorphism (Table 1). It is worth noting that, even if precursors $\mathbf{4 ,} 6$ and $\mathbf{8}$ are non-mesomorphic, P5-Cou-10 and P5-Cou-30 exhibit LC properties on account of the cooperative interactions between the coumarin moieties -a phenomenon which has also been observed in many LC polymers..$^{14,15}$

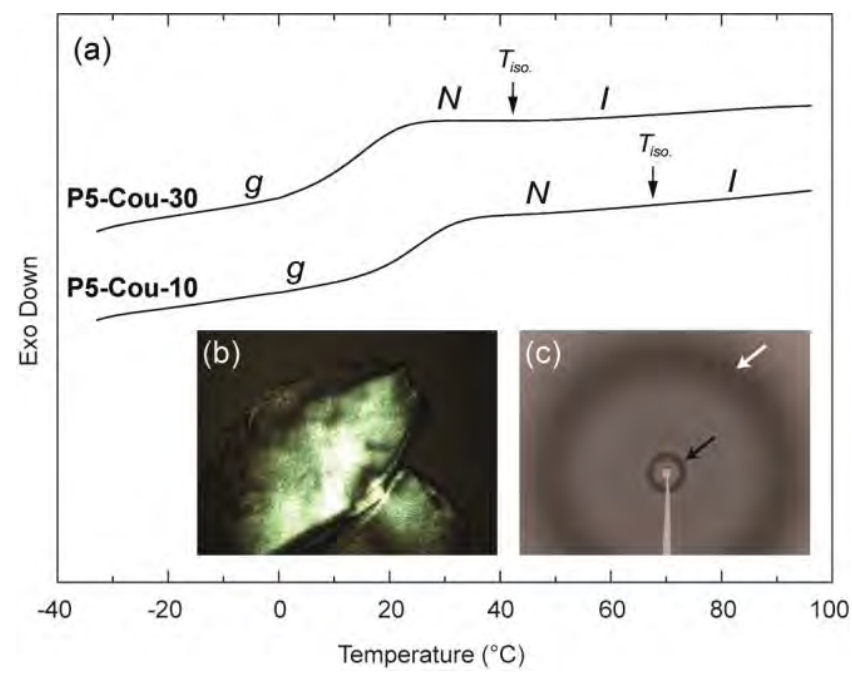

Figure 2. DSC thermograms corresponding to the second heating scan of P5-Cou-10 and P5-Cou-30 (a), POM microphotograph of a sample of P5-Cou-30 at $28^{\circ} \mathrm{C}$, second heating process (b), and room temperature XRD pattern of a sample of P5-Cou-30 after a thermal annealing at $100^{\circ} \mathrm{C}(\mathrm{c})$.

According to the optical textures and the X-ray diffraction (XRD) measurements, P5-Cou-10 and P5-Cou-30 exhibit nematic mesomorphism. The XRD patterns only showed diffuse scattering, which suggests the absence of long-range positional order (Figure 2c). A broad diffuse maximum was detected in the low-angle region (Figure $2 \mathrm{c}$, black arrow), which corresponds to the average distance between the molecules in the mesophase. By applying Bragg's law, a mean distance of $28-29 \AA$ is obtained for both compounds at room temperature in pristine samples and also after a thermal annealing at a temperature just above the nematic-to-isotropic transition. As the experimental distance obtained from our XRD measurements is similar for both P5-Cou-10 and P5-Cou-30, the diffuse scattering is associated with short-range intermolecular interactions in the direction parallel to the long axis of our pillar[5]arene derivatives. Such scattering pattern is consistent with a nematic mesophase; in a similar fashion to previous coumarin-containing LCMs synthesized in our laboratories. ${ }^{13}$ In the high-angle region of the patterns a broad, diffuse scattering maximum is observed (Figure $2 c$, white arrow), which corresponds to an approximate distance of 4.2-4.3 $\AA$. This scattering is characteristic of liquid crystal phases and associated with the lateral mesogen-to-mesogen (coumarin moieties) interactions. It is apparent that an increase in the number of peripheral coumarin moieties -from ten to thirty-reduces both the $T_{\mathrm{g}}$ and the nematic-to-isotropic transition temperature but does not alter the degree of the order of the mesophase to a significant extent. Pil$\operatorname{lar}[n]$ arenes $(n=5,6)$ derivatives exhibiting smectic and also columnar liquid crystal phases have been investigated in the last five-year period. ${ }^{11}$ In our case, we have shown that the functionalization of the rim of pillar [5]arene with coumarin moieties stabilizes a nematic liquid crystal order. Nematic liquid crystals are of interest due to their applications in electro-optical devices and biosensors; ${ }^{3-5}$ and the distinctive behavior of P5-Cou-10 and P5-dCou-30 -in comparison to previously reported liquid crystal pillar $[n]$ arenes and LCMscould open new routes for the development of useful materials and devices.

In keeping with the idea of exploiting the molecular recognition properties of LC pillar $[n]$ arenes as responsive materials in nanoporous systems, we have investigated the ability P5-Cou-10 and P5-Cou-30 to host small molecules in solution. We have selected 1,6-dicyanohexane (9, Chart 1$)$ as a guest molecule in reference to previous reports on pillar[5] arenes. ${ }^{11,16}$ The complexation of P5-Cou-30 and P5-Cou-10 with 9 was initially studied by ${ }^{1} \mathrm{H}$ NMR spectroscopy. The ${ }^{1} \mathrm{H}$ NMR spectrum of a 1:1 mixture of 9 and P5-Cou-30 in $\mathrm{CDCl}_{3}$, as an example, shows a series of additional new broad signals in the spectral region between $\delta=0$ and $-2 \mathrm{ppm}$ (Figure S20), which were absent in the spectra of the individual components. These resonances are associated with the 9СP5-Cou-30 complex, which exhibits slow exchange on the NMR time scale. The binding of $\mathbf{9}$ to P5-Cou-30 was also evidenced by 
the shifting of the signals of specific protons of the host. In the presence of 9, protons $\mathrm{H} \varphi$ and $\mathrm{H} \sigma$ of P5-Cou-30 slightly shift downfield whereas the signal corresponding to protons $\mathrm{H} \omega$ shifts upfield (Figure $1 \mathrm{~b})$. Such changes evidence the formation of the host-guest complex. ${ }^{11 \mathrm{~d}, 16}$ Analogous changes were found when 9 and P5-Cou10 were mixed in a $1: 1$ ratio.

$\mathrm{Li}$ and co-workers have recently shown that the liquid crystal properties of a macrocyclic cyclo[6] aramide derivatives may be altered to some extent when their cavities are occupied by small alkylammonium salts; and, a lamellar-to-hexagonal columnar transition was observed for one of their systems. ${ }^{9 \mathrm{~g}} \mathrm{We}$ wondered whether our host-guest complexes $\mathbf{9} \subset$ P5-Cou-10 and $9 \subset$ P5-Cou-30 would retain the nematic order of P5-Cou-10 and P5-Cou-30. Thus, 9 was dissolved in a $\mathrm{CDCl}_{3}$ solution containing an equimolar amount of P5-Cou-10 or P5-Cou-30; followed by solvent evaporation. The thermal and LC properties of the complexes were studied by a combination of POM, DSC and XRD. Freshly prepared samples of 9СP5-Cou-10 exhibited LC behavior, which was tentatively assigned as nematic according to our POM observations. Nevertheless, clear phase separation was detected on a series of optical microscopy observations when samples of $9 \subset$ P5-Cou-10 were heated above $55^{\circ} \mathrm{C}$ (Figure S31). Upon cooling, the phase separation persisted indicating that $9 \subset$ P5-Cou-10 irreversibly unbinds upon heating. Samples of 9СP5-Cou-30, on the other hand, were thermally stable and no phase separation was detected even after several cycles of heating and cooling. Similarly to P5-Cou-30, only a glass transition was detected on the thermogram of $9 \subset \mathbf{P 5 - C o u}-\mathbf{3 0}$. According to the optical textures, $\mathbf{9} \subset \mathbf{P 5 - C o u - 3 0}$ exhibits nematic mesomorphism, which is also supported by XRD. The binding of 9 to P5-Cou-30 does not alter the nature of the mesomorphism of the host molecule alone and only a reduction of the $T_{\mathrm{g}}$ was detected.

The electronic absorption spectra of P5-Cou-10 and P5-Cou-30 were recorded in solution $\left(\mathrm{CHCl}_{3}\right)$. The spectra corresponding to P5-Cou-10 and P5-Cou-30 are characterized by a strong absorption band with a maximum at around $325 \mathrm{~nm}$ corresponding to the $\pi-\pi^{*}$ transition of the coumarin moieties (Figure S32). Thin films for optical measurements were obtained by casting solutions of P5-Cou-10 and P5-Cou-30 onto clean quartz substrates. Attempts were also made to obtain thin films of alkynes $\mathbf{4}$ and $\mathbf{6}$, but the samples were not of good enough quality for optical measurements, which is likely on account of the crystalline or (semi)crystalline nature of 4 and 6. The films of P5-Cou-10 and P5-Cou-30 were heated up to $100{ }^{\circ} \mathrm{C}$ (isotropic state), and then rapidly cooled down to RT prior to our optical measurement. The electronic absorption spectra of P5-Cou-10 and P5-Cou-30 in thin film showed a main absorption band in the $250-350 \mathrm{~nm}$ region (Figure 3 ), associated with the coumarin moiety; which remained unaltered after the thermal annealing process.

Coumarin compounds exhibit a well-known photophysical and photochemical properties. ${ }^{17}$ They are capable of undergoing a reversible photoinduced $[2+2]$ cycloaddition by exposure to light of the appropriate frequency $(\lambda>300 \mathrm{~nm})$, leading to stable cyclobutane-based dimers. Such a cycloaddition provides a facile means of producing cross-linked films, which are desirable in applications requiring a certain degree of material robustness and solvent inertness. ${ }^{18}$ Thus, we evaluated the possibility of inducing cross-linking by exposing the thermally annealed films of P5-Cou-10 and
P5-Cou-30 to UV light. The electronic absorption spectra corresponding to a thin film of P5-Cou-30 before and after UV light exposure are shown in Figure 3. The significant decrease of the intensity of the main absorption band after irradiation is associated with the $[2+2]$ cycloaddition of the coumarin moieties. ${ }^{17}$ The successful cross-linking was demonstrated by soaking the samples in chloroform, which is a good solvent for both P5-Cou-10 and P5-Cou-30, for $2 \mathrm{~min}$. The appearance of the films was similar before and after the soaking process; confirming that the photo-induced cross-linking process proceed to a significant extent.

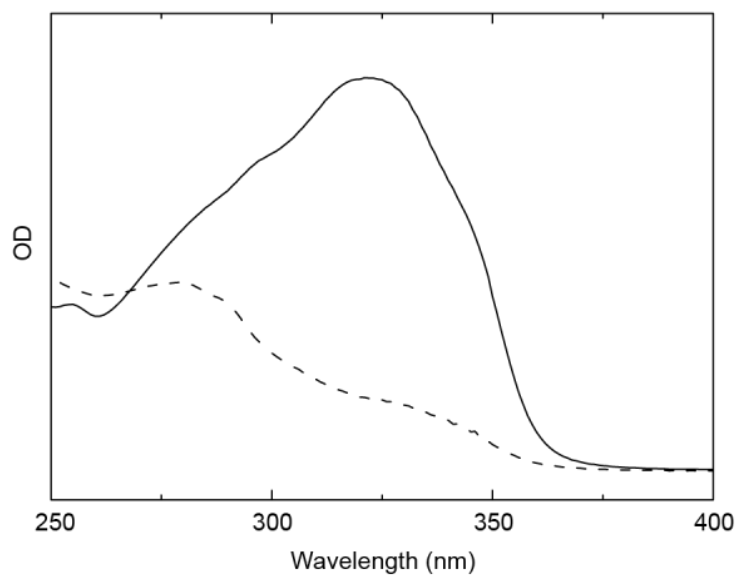

Figure 3. Electronic absorption spectra of a thermally treated film of P5-Cou-30 before (solid line) and after (dashed line) UV light irradiation.

The photo-polymerization of specific reactive monomers and polymers -including coumarin-containing compounds- with linearly polarized light (LPL) can induce uniaxial orientation of LCs when placed in contact with a film of the photo-reactive material after exposure to LPL. ${ }^{19}$ Such phenomenon is of interest in the production of patterned alignment layers for liquid crystal displays in a non-contact fashion. We envisioned that films of our pillar [5] arenes could be used in the micro-patterning of alignment layers. To evaluate this idea, we have performed a series of optical microscopy observations of LC cells with photo-alignment layers which were filled with E7 (Merck KGaA, Darmstadt, Germany), a low molecular weight LC.

Such LC cells consisted of two P5-Cou-30-coated substrates, which were exposed to LPL before assembling the cell. The bottom substrate was photo-cross-linked by exposure to LPL which, under our experimental conditions, imposes alignment parallel to the polarization direction of the light. ${ }^{20}$ The top substrate was exposed to LPL though a photolithographic mask with a pattern of lines. An initial irradiation step imposed a preferential alignment in the unmasked areas parallel to the lines of the pattern of the mask. After the first irradiation step, the mask was removed and the whole substrate was exposed to LPL with a polarization direction perpendicular to that of the first irradiation step. The cell was assembled in such a way that the alignment direction in the singly exposed areas of the top substrate was parallel to that of the bottom substrate. In this way, a planar alignment of the filling LC is expected in the areas which were protected by the photolithographic mask. A twisted nematic alignment is expected in the rest of the cell. A bright-dark pattern is observed when the lines are parallel to one of the polarizers and a nearly constant transmission is observed in the whole cell when the lines 
are at $45^{\circ}$ with respect to the microscope polarizers, which is consistent with the proposed LC director configuration (Figure 4) This indicates that a patterned alignment of LCs is achieved through a combination of photo-reactive pillar[5]arene alignment layers and photolithographic techniques.
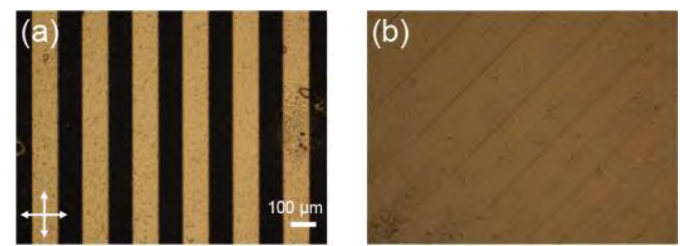

Figure 4. Optical micrographs, between crossed polarizers at $0^{\circ}(\mathrm{a})$ and $45^{\circ}$ (b) of a LC cell composed of P5-Cou-30 alignment layers and a filling nematic LC, E7.

\section{CONCLUSIONS}

In summary, we have demonstrated that the derivatization of pil$\operatorname{lar}[5]$ arene with coumarin-containing promesogenic moieties enables the preparation of LCMs with a shape-persistent central cavity. In contrast to previously reported LC pillar $[n]$ arenes, P5-Cou-10 and P5-Cou-30 are glassy materials exhibiting nematic mesomorphism at RT, which is retained over a relatively wide temperature range.

Host-guest complexes composed of 1,6-dicyanohexane and our pillar[5]derivatives have been obtained in solution and in the solid state, which evidences that the binding properties of pillar[5]arenes are shared by P5-Cou-10 and P5-Cou-30. The presence of the peripheral coumarin moieties provides P5-Cou-10 and P5-Cou-30 with enhanced film-forming and photoresponsive properties. Indeed, polymer networks have been obtained by photo-cross-linking thin films of P5-Cou-10 and P5-Cou-30, which is unique in comparison to previous LCMs. ${ }^{9-11}$ Such films can be used as alignment layers when LPL is employed in the photo-alignment process. Our coumarin-containing LC pillar[5] arenes exhibit a unique combination of properties and make way for potential applications in the field of multifunctional responsive materials.

\section{EXPERIMENTAL SECTION}

General Methods and Materials. All starting materials were purchased from Sigma-Aldrich and used as received unless stated otherwise. Compounds $\mathbf{1}, \mathbf{5}$, and $\mathbf{8}$ in Scheme 1 were synthesized according to previously described methods. ${ }^{11 b, 13}$ FTIR spectra were obtained on a Bruker Vertex 70 FT-IR spectrophotometer equipped with Specac Golden gate diamond ATR, 50 scans at a resolution of $4 \mathrm{~cm}^{-1}$ were carried out. Solution NMR experiments were carried out on Bruker Avance spectrometers operating at $400 / 500 \mathrm{MHz}$ for ${ }^{1} \mathrm{H}$ and $100 / 125 \mathrm{MHz}$ for ${ }^{13} \mathrm{C}$, using standard pulse sequences. Chemi$\mathrm{cal}$ shifts are given in ppm. The assignment of the signals of the NMR spectra was based on a series of 2D experiments. MALDI-TOF MS was performed on an Autoflex mass spectrometer (Bruker Daltonics) using dithranol as matrix. Mesogenic behavior was investigated by POM using an Olympus BH-2 polarizing microscope fitted with a Linkam THMS600 hot stage. TGA was performed using a Q5000IR from TA instruments at heating rate of $10^{\circ} \mathrm{C} \mathrm{min}{ }^{-1}$ under a nitrogen atmosphere. Thermal transitions were determined DSC using a DSC Q2000 from TA instruments with powdered samples $(2-5 \mathrm{mg})$ sealed in aluminum pans. Glass transition temperatures
$\left(T_{g}\right)$ were determined at the half height of the baseline jump, and first order transition temperatures were read at the maximum of the corresponding peak. XRD was performed with an evacuated Pinhole camera (Anton-Paar) operating a point-focused Ni-filtered $\mathrm{Cu}-\mathrm{K} \alpha$ beam. The patterns were collected on flat photographic films perpendicular to the X-ray beam. Powdered samples of the supramolecular complexes were placed in Lindemann glass capillaries $(0.9 \mathrm{~mm}$ diameter). UV-Vis absorption spectra were recorded on an ATIUnicam UV4-200 spectrophotometer.

Methyl 4-((11-((2-oxo-2H-chromen-7-yl)oxy) undecyl)oxy) benzoate (2). A mixture of 7-((11-bromoundecyl)oxy)-2Hchromen-2-one ( $3 \mathrm{~g}, 7.63 \mathrm{mmol}){ }_{1}^{13}$ methyl 4-hydroxybenzoate $(1.16 \mathrm{~g}, 7.63 \mathrm{mmol})$, potassium carbonate $(2.11 \mathrm{~g}, 15.25 \mathrm{mmol})$, a teaspoon of potassium iodide and acetone $(50 \mathrm{~mL})$ was stirred and heated under reflux for $24 \mathrm{~h}$. The reaction mixture was allowed to cool down to RT and the solids were filtered off and washed with acetone. The solvent was evaporated and the crude product was purified by flash column chromatography on silica gel using DCM as eluent. Yield: $83 \%(2.97 \mathrm{~g})$. IR $(\mathrm{KBr}) \vee\left(\mathrm{cm}^{-1}\right): 2920,1723,1615$, $1506,1469,1244,1149 .{ }^{1} \mathrm{H}$ NMR $\left(\mathrm{CDCl}_{3}, 400 \mathrm{MHz}\right): \delta 8.04-7.88$ $(\mathrm{m}, 2 \mathrm{H}), 7.68-7.56(\mathrm{~m}, 1 \mathrm{H}), 7.41-7.30(\mathrm{~m}, 1 \mathrm{H}), 6.96-6.75(\mathrm{~m}, 4 \mathrm{H})$, 6.29-6.17 (m, 1H), 4.07-3.92 (m, 4H), 3.87 (s, 3H), 1.86-1.71 (m, $4 \mathrm{H}), 1.53-1.25(\mathrm{~m}, 14 \mathrm{H}) .{ }^{13} \mathrm{C}\left\{{ }^{1} \mathrm{H}\right\}$ NMR $\left(\mathrm{CDCl}_{3}, 100 \mathrm{MHz}\right): \delta$ 167.1, 163.2, 163.0, 161.4, 156.3, 143.9, 131.7, 129.3, 122.5, 114. 6, $113.4,113.0,101.7,73.9,69.7,69.3,52.5,52.0,30.9,30.3,30.2,30.1$, 30.0, 29.9, 29.6, 26.6, 26.5. HRMS $\left(\mathrm{ESI}^{+}\right): m / z[\mathrm{M}+\mathrm{H}]^{+}$calcd for $\mathrm{C}_{28} \mathrm{H}_{35} \mathrm{O}_{6}, 467.2434$; found, 467.2431.

4-((11-((2-Oxo-2H-chromen-7-yl)oxy) undecyl)oxy) benzoic acid (3). An aqueous solution of potassium hydroxide ( $3.00 \mathrm{~g}$, $5 \mathrm{~mL}$ ) was added to a solution of compound $2(2.50 \mathrm{~g}, 5.36 \mathrm{mmol})$ in THF-methanol 1:1 $(50 \mathrm{~mL})$. The mixture was stirred and heated under reflux and the evolution of the reaction was followed by thilayer chromatography. The mixture was stirred and heated under reflux for $2 \mathrm{~h}$. Then the crude product was precipitated by addition of concentrated hydrochloric acid until $\mathrm{pH} 2$ and it was filtered and washed with water. Yield: $94 \%(2.28 \mathrm{~g})$. IR $(\mathrm{KBr}) \vee\left(\mathrm{cm}^{-1}\right): 3133$, 2927, 1689, 1619, 1512, 1466, 1225, 1139. ${ }^{1} \mathrm{H}$ NMR $\left(\mathrm{CDCl}_{3}, 400\right.$ MHz: $\delta$ 8.02-7.94 $(\mathrm{m}, 2 \mathrm{H}), 7.70-7.60(\mathrm{~m}, 1 \mathrm{H}), 7.43-7.32(\mathrm{~m}, 1 \mathrm{H})$, 6.95-6.72 (m, 4H), 6.27-6.18 (m, 1H), 4.05-3.91 (m, 4H), 1.87-1.70 (m, 4H), 1.57-1.22 (m, 14H $).{ }^{13} \mathrm{C}\left\{{ }^{1} \mathrm{H}\right\}$ NMR $\left(\mathrm{CDCl}_{3}, 100 \mathrm{MHz}\right)$ : $\delta 171.8,163.5,163.0,161.4,156.3,143.9,132.5,129.3,121.5,114.3$, $113.4,113.0,101.7,73.9,69.7,69.3,52.5,30.9,30.2,30.2,30.2,30.0$, 29.9, 29.6, 26.7, 26.6. HRMS $\left(\mathrm{ESI}^{+}\right): \mathrm{m} / z[\mathrm{M}+\mathrm{Na}]^{+}$calcd for $\mathrm{C}_{27} \mathrm{H}_{32} \mathrm{NaO}_{6}, 475.2097$; found, 475.2070.

Propargyl 4-((11-((2-oxo-2H-chromen-7-yl) oxy $)$ undecyl) oxy)benzoate (4). Compound $3(2.00 \mathrm{~g}, 4.42 \mathrm{mmol})$, propargyl alcohol $(0.27 \mathrm{~g}, 4.86 \mathrm{mmol})$ and 4-(dimethylamino)pyridinium $p$-toluenesulfonate $(0.69 \mathrm{~g}, 2.21 \mathrm{mmol})$ were dissolved in anhydrous DCM $(15 \mathrm{~mL})$. The reaction flask was cooled in an ice bath and flushed with argon, then $N, N$ '-dicyclohexylcarbodiimide $(1.37 \mathrm{~g}, 6.63 \mathrm{mmol})$ was added dropwise. The mixture was stirred at RT for $24 \mathrm{~h}$ under argon atmosphere. The solvent was evaporated and the crude product was purified by flash column chromatography on silica gel using DCM as eluent and gradually changing the composition of the eluent to DCM/ethyl acetate $(9: 1)$. Then the product was recrystallized in acetone. Yield: $91 \%(1.97 \mathrm{~g})$. IR (KBr) v $\left(\mathrm{cm}^{-1}\right): 3295,3076,2917,1725,1628,1616,1470,1128 .{ }^{1} \mathrm{H}$ NMR 
$\left(\mathrm{CD}_{2} \mathrm{Cl}_{2}, 500 \mathrm{MHz}\right): \delta 8.06-7.94(\mathrm{~m}, 2 \mathrm{H}), 7.65-7.59(\mathrm{~m}, 1 \mathrm{H}), 7.37-$ $7.371(\mathrm{~m}, 1 \mathrm{H}), 6.96-6.86(\mathrm{~m}, 2 \mathrm{H}), 6.84-6.75(\mathrm{~m}, 2 \mathrm{H}), 6.25-6.20(\mathrm{~m}$, $1 \mathrm{H}), 4.89(\mathrm{~d}, J=2.4 \mathrm{~Hz}, 2 \mathrm{H}), 4.05-3.96(\mathrm{~m}, 4 \mathrm{H}), 2.50(\mathrm{t}, J=2.4 \mathrm{~Hz}$, $1 \mathrm{H})$, 1.86-1.70 (m, 4H), 1.53-1.27 (m, 14H). ${ }^{13} \mathrm{C}\left\{{ }^{1} \mathrm{H}\right\}$ NMR $\left(\mathrm{CDCl}_{3}, 125 \mathrm{MHz}\right): \delta 163.3,162.4,161.3,155.9,143.5,131,9$, 128.7, 121.5, 114.2, 113.0, 112.9, 112.4, 101.3, 78.0, 74.8, 69.7, 68.2, 52.1, 29.5, 29.5, 29.3, 29.1, 29.0, 26.0, 25.9. HRMS (ESI $\left.{ }^{+}\right): m / z$ $[\mathrm{M}+\mathrm{Na}]^{+}$calcd for $\mathrm{C}_{30} \mathrm{H}_{34} \mathrm{NaO}_{6}, 513.2253$; found, 513.2214.

P5-Cou-10. A Schlenk flask was charged with 8 (31.4 mg, 0.034 $\mathrm{mmol}),{ }^{1 \mathrm{~b}} 4(250 \mathrm{mg}, 0.51 \mathrm{mmol})$, sodium ascorbate $(6.7 \mathrm{mg}$, $0.034 \mathrm{mmol})$ and THF ( $3 \mathrm{~mL})$. Copper (II) sulfate pentahydrate (4.2 $\mathrm{mg}, 0.017 \mathrm{mmol}$ ) was dissolved in water $(1 \mathrm{~mL})$ and was added to the reaction. The reaction flask was degassed by three freezepump-thaw cycles and flushed with argon. The reaction mixture was stirred at $40^{\circ} \mathrm{C}$ for 5 days. Then, the azide-functionalized resin was added under argon flow to remove azide excess and the reaction mixture was stirred for further $24 \mathrm{~h}$. The resin was filtered off, the mixture was diluted with THF and then passed through a short column of aluminum oxide, using THF as eluent, to remove copper salts. The solvent was evaporated and the crude product was purified by flash column chromatography on silica gel using DCM as eluent and gradually changing the composition of the eluent to DCM/ethyl acetate (8:2). Yield: $38 \%(80.5 \mathrm{mg})$. IR (neat) $\vee\left(\mathrm{cm}^{-1}\right): 2923,1726$, 1613, 1246, 1151. ${ }^{1} \mathrm{H}$ NMR $\left(\mathrm{CD}_{2} \mathrm{Cl}_{2}, 400 \mathrm{MHz}\right): \delta 8.05-7.95(\mathrm{~m}$, $10 \mathrm{H}), 7.88-7.77(\mathrm{~m}, 20 \mathrm{H}), 7.68-7.60(\mathrm{~m}, 10 \mathrm{H}), 7.43-7.34(\mathrm{~m}$, $10 \mathrm{H}), 6.87-6.74(\mathrm{~m}, 40 \mathrm{H}), 6.56-6.45(\mathrm{~m}, 10 \mathrm{H}), 6.23-6.13(\mathrm{~m}$, $10 \mathrm{H})$, 5.47-5.36 (m, 20H), 4.91-4.68 (m, 20H), 4.30-4.09 (m, $20 \mathrm{H})$, 4.08-3.91 (m, 40H), 3.29-3.13 (m, 10H), 1.88-1.67 (m, $40 \mathrm{H}), 1.52-1.23(\mathrm{~m}, 140 \mathrm{H}) .{ }^{13} \mathrm{C}\left\{{ }^{1} \mathrm{H}\right\} \mathrm{NMR}\left(\mathrm{CD}_{2} \mathrm{Cl}_{2}, 100 \mathrm{MHz}\right): \delta$ $166.4,163.7,163.0,161.4,156.5,149.6,143.9,132.1,129.3,129.2$, 125.2 , 122.4, 115.6, 114.6, 113.4, 113.3, 113.0, 101.8, 69.3, 68.9, 67.6, 58.4, 50.8, 30.1, 30.0, 29.9, 29.7, 29.6, 26.5, 26.5. MS (MALDI', dithranol): $m / z[\mathrm{M}+\mathrm{Na}]^{+}$calcd for $\mathrm{C}_{355} \mathrm{H}_{400} \mathrm{~N}_{30} \mathrm{NaO}_{70}, 6230.13$; found, 6229.00 .

Propargyl 3,4,5-tris ((11-((2-oxo-2H-chromen-7-yl)oxy) undecyl)oxy)benzoate (6). 3,4,5-Tris((11-((2-oxo-2H-chromen-7yl)oxy)undecyl)oxy)benzoic acid (1.00 g, $0.90 \mathrm{mmol}),{ }^{13}$ propargyl alcohol (75.5 mg, $1.35 \mathrm{mmol}$ ) and 4-(dimethylamino)pyridinium $p$-toluenesulfonate $(0.14 \mathrm{~g}, 0.45 \mathrm{mmol})$ were dissolved in anhydrous DCM $(15 \mathrm{~mL})$. The reaction flask was cooled in an ice bath and flushed with argon, then $N, N^{\prime}$-dicyclohexylcarbodiimide (0.28 g, $1.35 \mathrm{mmol}$ ) was added dropwise. The mixture was stirred at RT for $24 \mathrm{~h}$ under argon atmosphere. The solvent was evaporated and the crude product was purified by flash column chromatography on silica gel using DCM as eluent and gradually changing the composition of the eluent to DCM/ethyl acetate (9:1). Then the product was recrystallized in acetone. Yield: $94 \%$ (0.98 g). IR (KBr) v $\left(\mathrm{cm}^{-1}\right): 3296,3080,2920,1724,1628,1615,1469 .{ }^{1} \mathrm{H}\left(\mathrm{CD}_{2} \mathrm{Cl}_{2}\right.$, $500 \mathrm{MHz}): \delta 7.65-7.59(\mathrm{~m}, 3 \mathrm{H}), 7.37-7.371(\mathrm{~m}, 3 \mathrm{H}), 7.27(\mathrm{~s}, 2 \mathrm{H})$, 6.84-6.75 (m, 6H), 6.25-6.20 (m, 3H), $4.89(\mathrm{~d}, J=2.4 \mathrm{~Hz}, 2 \mathrm{H}), 4.05-$ $3.96(\mathrm{~m}, 12 \mathrm{H}), 2.50(\mathrm{t}, J=2.4 \mathrm{~Hz}, 1 \mathrm{H}), 1.86-1.70(\mathrm{~m}, 12 \mathrm{H}), 1.53-$ $1.27(\mathrm{~m}, 42 \mathrm{H}) .{ }^{13} \mathrm{C}\left\{{ }^{1} \mathrm{H}\right\}$ NMR $\left(\mathrm{CDCl}_{3}, 125 \mathrm{MHz}\right): \delta$ 165.6, 162.4, 161.3, 156.0, 152.9, 143.4, 142.8, 128.7, 123.9, 113.0, 112.9, 112.4, $108.3,101.3,77.9,74.9,73.5,69.2,68.7,52.4,30.3,29.7,29.6,29.5$, 29.4, 29.4. HRMS $\left(\mathrm{ESI}^{+}\right): m / z[\mathrm{M}+\mathrm{Na}]^{+}$calcd for $\mathrm{C}_{70} \mathrm{H}_{86} \mathrm{NaO}_{14}$, 1173.5915; found, 1173.5902 .
P5-Cou-30. A Schlenk flask was charged with 8 (13.4 mg, 0.0145 $\mathrm{mmol}),{ }^{11 \mathrm{~b}} 6(250 \mathrm{mg}, 0.217 \mathrm{mmol})$, sodium ascorbate $(2.9 \mathrm{mg}$, $0.0145 \mathrm{mmol}$ ) and THF (3 mL). Copper (II) sulfate pentahydrate $(1.8 \mathrm{mg}, 0.0072 \mathrm{mmol})$ was dissolved in water $(1 \mathrm{~mL})$ and was added to the reaction. The reaction flask was degassed by three freeze-pump-thaw cycles and flushed with argon. The reaction mixture was stirred at $40^{\circ} \mathrm{C}$ for 5 days. Then, the azide-functionalized resin was added under argon flow to remove azide excess and the reaction mixture was stirred for further $24 \mathrm{~h}$. The resin was filtered off, the mixture was diluted with THF and then passed through a short column of aluminum oxide, using THF as eluent, to remove copper salts. The solvent was evaporated and the crude product was purified by flash column chromatography on silica gel using DCM as eluent and gradually changing the composition of the eluent to DCM/ethyl acetate (8:2). Yield: $43 \%(80.3 \mathrm{mg})$. IR (neat) $\vee\left(\mathrm{cm}^{-1}\right): 2920,1726$, $1611,1245,1145 .{ }^{1} \mathrm{H}$ NMR $\left(\mathrm{CDCl}_{3}, 500 \mathrm{MHz}\right): \delta 7.99(\mathrm{~m}, 10 \mathrm{H})$, 7.66-7.52 (m, 30H), 7.37-7.28 (m, 30H), 7.22-7.11 (m, 20H), 6.85$6.67(\mathrm{~m}, 60 \mathrm{H}), 6.59-6.45(\mathrm{~m}, 10 \mathrm{H}), 6.24-6.13(\mathrm{~m}, 30 \mathrm{H}), 5.48-5.36$ $(\mathrm{m}, 20 \mathrm{H}), 4.86-4.60(\mathrm{~m}, 20 \mathrm{H}), 4.38-4.05(\mathrm{~m}, 20 \mathrm{H}), 4.05-3.80(\mathrm{~m}$, $120 \mathrm{H}), 3.31-3.09(\mathrm{~m}, 10 \mathrm{H}), 1.90-1.61(\mathrm{~m}, 120 \mathrm{H}), 1.52-1.11(\mathrm{~m}$, $420 \mathrm{H}) .{ }^{13} \mathrm{C}\left\{{ }^{1} \mathrm{H}\right\} \mathrm{NMR}\left(\mathrm{CDCl}_{3}, 125 \mathrm{MHz}\right): \delta 166.2,162.4,161.2$, $155.9,152.8,149.5,143.4,143.2,142.6,128.7,124.9,124.3,116.0$ $112.9,112.4,108.1,101.3,73.5,69.2,68.6,67.5,58.0,50.3,30.4$, 29.7, 29.6, 29.6, 29.5, 29.4, 29.0, 26.2, 26.1, 26.0. MS (MALDI ${ }^{+}$, dithranol): $m / z[\mathrm{M}+\mathrm{Na}]^{+}$calcd for $\mathrm{C}_{755} \mathrm{H}_{920} \mathrm{~N}_{30} \mathrm{NaO}_{150}, 12838.50$; found, 12838.58 .

Optical Measurements in Thin Films and Liquid Crystal Cells. Thin polymer films for optical measurements were prepared by casting THF solutions of P5-Cou-10 and P5-Cou-30 (about 0.1 wt. \%) onto clean quartz substrates. Before performing the optical measurements, films were heated at $100^{\circ} \mathrm{C}$ for $1 \mathrm{~min}$ and rapidly quenched to RT. A Varian Cary 500 UV-Visible-IR spectrophotometer was used for optical absorption measurements. For dichroism measurements, a linear polarizer was placed in front of the film with the transmission direction either parallel or perpendicular to the polarization of the UV light employed for the curing of the coumarin-containing materials. For the photo-cross-linking studies, the thermally annealed thin films of P5-Cou 10 and P5-Cou-30 were irradiated with UV light $\left(17.8 \mathrm{~mW} \cdot \mathrm{cm}^{-2}\right)$ for $15 \mathrm{~min}$ (Figure 3 ). The photo-alignment experiments were carried out using an Ominicure S2000 UV lamp provided with a 320-390 nm filter. A Knight Optical HNBP sheet UV polarizer was used to polarize the UV light. In the liquid crystal alignment studies, an empty cell coated with a thin film of P5-Cou-30 on the inner side of each substrate (glass slides) was assembled and the gap between the substrates was fixed by using $10 \mu \mathrm{m}$ diameter glass spacers. In a preliminary set of experiment, the two substrates of the cell were flood exposed to LPL and the cell was assembled in such a way that the polarization directions of the light employed in each of the exposures -one per substratewas parallel to each other. The cell was filled with the low molecular weight LC E7 (Merck KGaA, Darmstadt, Germany) at $70^{\circ} \mathrm{C}$ leading to a monodomain cell with planar alignment at RT. To determine the director orientation with respect the polarization direction of the UV light (employed for photo-alignment process), the blue colored dichroic dye Rhodamine 700 (Lambda Physik AG, Goettingen, Germany) was incorporated to the LC. A series of polarized absorption measurements were carried out on this sample and showed a more intense absorption when the polarization direction of the probe light 
beam was parallel to the direction of the UV light of the photo-alignment process (Figure S33). As Rhodamine 700 aligns parallel to the LC director, ${ }^{21}$ we concluded that LPL induces alignment of the LCs parallel to the polarization of the UV light used in the photo-alignment process. In the following set of experiments, and before the cell was assembled, the P5-Cou-30 coated substrates were exposed to LPL as follows. The bottom substrate was exposed to LPL ( 0.8 $\left.\mathrm{mW} \cdot \mathrm{cm}^{-2}\right)$ for $10 \mathrm{~min}$. The top substrate was irradiated twice. Initially, the substrate was exposed to LPL $\left(0.8 \mathrm{~mW} \cdot \mathrm{cm}^{-2}, 10 \mathrm{~min}\right)$ through a photolithographic mask, imposing a preferential alignment in the unmasked areas parallel to the lines of the pattern of the mask. Following this, the mask was removed and the whole substrate was exposed to LPL $\left(0.8 \mathrm{~mW} \cdot \mathrm{cm}^{-2}, 2 \mathrm{~min}\right)$ with a polarization direction orthogonal to that of the first irradiation step. It is important to note that the light dose of each irradiation step was adjusted to ensure an efficient alignment in the singly-exposed areas without compromising the alignment achieved after the first irradiation step (in the presence of the mask). Afterwards, the cell was assembled in such a way that the alignment direction in the masked areas of the top substrate was parallel to that of the bottom substrate. After the assembly of the cell was completed, the cell gap was filled with E7 at $70^{\circ} \mathrm{C}$. Once the cell gap was completely filled, the cell was slowly cooled down to RT in order to ensure that the filling liquid crystal followed the orientation imposed by the photo-alignment layers (Figure 4).

\section{ASSOCIATED CONTENT}

The Supporting Information is available free of charge at http://pubs.acs.org

${ }^{1} \mathrm{H},{ }^{13} \mathrm{C}$ and bidimensional NMR spectra, mass spectra, thermogravimetric analysis curves and DSC thermograms. Additional UV-Vis spectroscopy measurements and POM and XRD studies.

\section{AUTHOR INFORMATION}

\section{Corresponding Author}

*E-mail: jdb529@unizar.es

\section{Present Addresses}

"Department of Chemistry, Massachusetts Institute of Technology, MA 02139, Cambridge, United States.

\section{Author Contributions}

${ }^{\S}$ A.C. and J.D.B. contributed equally.

\section{Notes}

The authors declare no competing financial interests.

\section{ACKNOWLEDGMENTS}

J.D.B. acknowledges the MINECO, the FSE, and the FEDER for funding through projects RYC-2015-18471 (Ramón y Cajal program) and CTQ2017-84087-R. T.O. acknowledges funding from JST CREST. C.S.-S. acknowledges the MINECO for funding through project BIO2017-84246-C2-1-R, Gobierno de Aragón for project LMP150_18 and FEDER (EU). J.L.S acknowledges the MINECO for funding through project PGC2018-097583-B-I00, FEDER, and Gobierno de Aragón (Research Group E47_17R). The authors thank access to the services of CEQMA (Nuclear Magnetic Resonance, Mass Spectra, and
Thermal Analysis) of the Universidad de Zaragoza-CSIC. A.C. thanks MINECO for a PhD fellowship.

\section{REFERENCES}

(1) Handbook of Liquid Crystals, 2nd ed. (Eds.: J. W. Goodby, P. J. Collings, H. Gleeson, P. Raynes, T. Kato, C. Tschierske), Wiley-VCH, Weinheim, 2014.

(2) (a) Li, Q. (Ed.), Liquid Crystals Beyond Displays: Chemistry, Physics, and Applications, Wiley, Hoboken, 2012. (b) Li, Q. (Ed.), Photoactive Functional Soft Materials: Preparation, Properties, and Applications, Wiley-VCH, Weinheim, 2019. (c) Bisoyi, H. K.; Li, Q. Light-driven liquid crystalline materials: from photo-induced phase transitions and property modulations to applications. Chem. Rev. 2016, 116, 15089-15116.

(3) (a) van der Asdonk, P.; Kouwer, P. H. J. Liquid crystal templating as an approach to spatially and temporally organise soft matter. Chem. Soc. Rev. 2017, 46, 5935-5949. (b) Broer, D. J.; Bastiaansen, C. M. W.; Debije, M. G.; Schenning, A. P. H. J. Functional organic materials based on polymerized liquid-crystal monomers: Supramolecular hydrogen-bonded systems. Angew. Chem. Int. Ed. 2012, 51, 7102-7109.

(4) (a) Kato, T.; Yoshio, M.; Ichikawa, T.; Soberats, B.; Ohno, H.; Funahashi, M. Transport of ions and electrons in nanostructured liquid crystals. Nat. Rev. Mater. 2017, 2, 17001. (b) Cho, J.; Ishida, Y. Macroscopically oriented porous materials with periodic ordered structures: From zeolites and metal-organic frameworks to liquid-crystal-templated mesoporous materials. Adv. Mater., 2017, 29, 1605974.

(5) (a) Woltman, S.J.; Jay, G. D.; Crawford, G. P.Liquid-crystal materials find a new order in biomedical applications. Nat. Mater. 2007, 6, 929. (b) Schenning, A. (Ed.), Crawford, G. (Ed.), Broer, D. (Ed.), Liquid Crystal Sensors. Boca Raton: CRC Press, 2018 (c) Concellón, A.; Zentner, C. A.; Swager, T. M. Dynamic complex liquid crystal emulsions. J. Am. Chem. Soc. 2019, 141, 18246-18255. (d) López-Valdeolivas, M.; Liu, D.; Broer, D. J.; Sánchez-Somolinos, C. 4D printed actuators with soft robotic functions. Macromol. Rapid Commun. 2018, 39, 1700710. (e) Kato, T.; Uchida, J.; Ichikawa, T.; Sakamoto, T. Functional liquid crystals towards the next generation of materials. Angew. Chem. Int. Ed. 2018, 57, 4355-4371. (f) Wang, Y; Li, Q. Light-Driven Chiral Molecular Switches or Motors in Liquid Crystals. Adv. Mater. 2012, 24, 1926-1945.

(6) (a) Tschierske, C. Development of structural complexity by liquid-crystal self-assembly. Angew. Chem. Int. Ed. 2013, 52, 8828-8878. (b) Kato, T.; Mizoshita, N.; Kishimoto, K. Functional liquid-crystalline assemblies: Self-organized soft materials. Angew. Chem. Int. Ed. 2006, 45, 38-68. (c) Lugger, J. A. M.; Mulder, D.J.; Sijbesma, R. P.; Schenning, A. P. H.J. Nanoporous polymers based on liquid crystals. Materials 2018, 11, 104. (d) Sakamoto, T.; Ogawa, T.; Nada, H.; Nakatsuji, K.; Mitani, M.; Soberats, B.; Kawata, K.; Yoshio, M.; Tomioka, H.; Sasaki, T.; Kimura, M.; Henmi, M.; Kato, T. Development of nanostructured water treatment membranes based on thermotropic liquid crystals: Molecular design of sub-nanoporous materials Adv. Sci. 2018, 5, 1700405. (e) Cavallo, G.; Terraneo, G.; Monfredini, A.; Saccone, M.; Priimagi, A.; Pilati, T.; Resnati, G.; Metrangolo, P.; Bruce, D. W. Superfluorinated ionic liquid crystals based on supramolecular, halogen-bonded anions Angew. Chem. Int. Ed. 2016, 55, 6300-6304.

(7) (a) Lugger, J. A. M.; Mulder, D. J.; Bhattacharjee, S.; Sijbesma, R. P. Homeotropic self-alignment of discotic liquid crystals for nanoporous polymer films ACS Nano 2018, 12, 6714-6724. (b) Concellón, A.; Schenning, A. P. H. J.; Romero, P.; Marcos, M.; Serrano, J. L. Size-selective adsorption in nanoporous polymers from coumarin photo-cross-linked columnar liquid crystals Macromolecules 2018, 51, 2349-2358. (c) Feng, X.; Kawabata, K.; Kaufman, G.; Elimelech, M.; Osuji, C. O. Highly selective vertically aligned nanopores in sustainably derived polymer membranes by molecular templating ACS Nano 2017, 11, 3911-3921. (d) del Barrio, J.; Liu, J.; Brady, R. A.; Tan, C. S. Y.; Chiodini, S.; Ricci, M.; Fernández-Leiro, R.; Tsai, C.-J.; Vasileiadi, P.; Di Michele, L.; Lairez, D.; Toprakcioglu, C.; Scherman, O. A. Emerging two-dimensional crystallization of cucurbit[8] 
uril complexes: From supramolecular polymers to nanofibers J. Am. Chem. Soc. 2019, 141, 14021-14025.

(8) Wöhrle, T.; Wurzbach, I.; Kirres, J.; Kostidou, A.; Kapernaum, N.; Litterscheidt, J.; Haenle, J. C.; Staffeld, P.; Baro, A.; Giesselmann, F.; Laschat, S. Discotic liquid crystals. Chem. Rev. 2016, 116, 1139-1241.

(9) (a) Zhang, J.; Moore, J. S. Liquid crystals based on shape-persistent macrocyclic mesogens J. Am. Chem. Soc. 1994, 116, 2655-2656. (b) Baranoff, E. D.; Voignier, J.; Yasuda, T.; Heitz, V.; Sauvage, J.-P.; Kato, T.A liquid-crystalline [2] catenane and its copper(I) complex. Angew. Chem. Int. Ed. 2007, 46, 4680-4863. (c) Sato, K.; Itoh, Y.; Aida, T. Columnarly assembled liquid-crystalline peptidic macrocycles unidirectionally orientable over a large area by an electric field. J. Am. Chem. Soc. 2011, 133, 13767-13769. (d) Casal-Dujat, L.; Penon, O.; Rodríguez-Abreu, C.; Solans, C.; Pérez-García, L. Macrocyclic ionic liquid crystals. New J. Chem. 2012, 36, 558-561. (e) Suhan, N. D.; Loeb, S. J.; Eichhorn, H. Mesomorphic [2]rotaxanes: Sheltering ionic cores with interlocking components J. Am. Chem. Soc. 2013, 135, 400-408. (f) Kawano, S.; Kato, M.; Soumiya, S.; Nakaya, M.; Onoe, J.; Tanaka, K. Columnar liquid crystals from a giant macrocycle mesogen. Angew. Chem. Int. Ed. 2018, 57, 167-171. (g) Li, X.; Li, B.; Chen, L.; Hu, J.; Wen, C.; Zheng, Q.; Wu, L.; Zeng, H.; Gong, B.; Yuan, L. Liquid-crystalline mesogens based on cyclo[6]aramides: Distinctive phase transitions in response to macrocyclic host-guest interactions. Angew. Chem. Int. Ed. 2015, 54, 11147-11152.

(10) (a) Ogoshi, T.; Yamagishi, T.; Nakamoto, Y. Pillar-shaped macrocyclic hosts pillar[n]arenes: New key players for supramolecular chemistry. Chem. Rev. 2016, 116, 7937-8002.

(11) (a) Nierengarten, I.; Guerra, S.; Holler, M.; Nierengarten, J. F.; Deschenaux, R. Building liquid crystals from the 5-fold symmetrical pillar[5]arene core Chem. Commun. 2012, 48, 8072-8074. (b) Nierengarten, I.; Guerra, S.; Holler, M.; Karmazin-Brelot, L.; Barberá, J.; Deschenaux, R.; Nierengarten, J. F. Macrocyclic effects in the mesomorphic properties of liquid-crystalline pillar[5]- and pillar[6]arenes. Eur. J. Org. Chem. 2013, 18, 3675-3684. (c) Pan, S.; Ni, M.; Mu, B.; Li, Q.; Hu, X. Y.; Lin, C.; Chen, D.; Wang, L. Well-defined pillararene-based azobenzene liquid crystalline photoresponsive materials and their thin films with photomodulated surfaces. Adv. Funct. Mater. 2015, 25, 3571-3580. (d) Nierengarten, I.; Guerra, S.; Ben Aziza, H.; Holler, M.; Abidi, R.; Barberá, J.; Deschenaux, R.; Nierengarten, J.-F. Piling up pillar[5]arenes to selfassemble nanotubes. Chem. Eur. J. 2016, 22, 6185-6189.

(12) (a) He, J.; Zhao, Y.; Zhao, Y. Photoinduced bending of a coumarincontaining supramolecular polymer. Soft Matter 2009, 5, 308-310. (b) Zhao, L.; Loy, D. A.; Shea, K. J. Photodeformable spherical hybrid nanoparticles J. Am. Chem. Soc. 2006, 128, 14250-14251. (c) Maddipatla, M. V.S. N.; Wehrung, D.; Tang, C.; Fan, W.; Oyewumi, M. O.; Miyoshi, T.;
Joy, A. Photoresponsive coumarin polyesters that exhibit cross-linking and chain scission properties. Macromolecules 2013, 46, 5133-5140.

(13) Concellón, A.; Marcos, M.; Romero, P.; Serrano, J. L.; Termine, R.; Golemme, A. Not only columns: High hole mobility in a discotic nematic mesophase formed by metal-containing porphyrin-core dendrimers. Angew. Chem. Int. Ed. 2017, 56, 1259-1263.

(14) Natansohn, A.; Rochon, P.Photoinduced motions in azo containing polymers Chem. Rev. 2002, 102, 4139-4176.

(15) Chinelatto, L. S., Jr.; del Barrio, J.; Piñol, M.; Oriol, L.; Matranga, M. A.; De Santo, M. P.; Barberi, R. Oligofluorene blue emitters for cholesteric liquid crystal lasers J. Photochem. Photobiol., A 2010, 210, 2-3, 130-139.

(16) Shu, X.; Chen, S.; Li, J.; Chen, Z.; Weng, L.; Jia, X.; Li, C. Highly effective binding of neutral dinitriles by simple pillar[5]arenes. Chem. Commun. 2012, 48, 2967-2969.

(17) (a) Trenor, S. R.; Shultz, A. R.; Love, B.J.; Long, T. E. Coumarins in polymers: From light harvesting to photo-cross-linkable tissue scaffolds. Chem. Rev. 2004, 104, 3059-3077. (b) del Barrio, J.; Sánchez-Somolinos, C. Light to shape the future: From photolithography to $4 \mathrm{D}$ printing. Adv. Opt. Mater. 2019, 1900598.

(18) Blasco, E.; Wegener, M.; Barner-Kowollik, C. Photochemically driven polymeric network formation: Synthesis and applications Adv. Mater. 2017, 1604005.

(19) Kim, C.; Trajkovska, A.; Wallace, J. U.; Chen, S. H. New insight into photoalignment of liquid crystals on coumarin-containing polymer films. Macromolecules 2006, 39, 3817-3823.

(20) The alignment of E7 was verified by a series of preliminary experiments with LC cells, which were coated with the coumarin-containing pillar[5]arenes and exposed to LPL (see Experimental Section for more details).

(21) de Haan, L. T.; Sánchez-Somolinos, C.; Bastiaansen, C. M. W.; Schenning, A. P. H. J.; Broer, D. J. Engineering of complex order and the macroscopic deformation of liquid crystal polymer networks. Angew. Chem., Int. Ed. 2012, 51, 12469-12640. 